\title{
The Cutoff Value of HbA1c in Predicting Diabetes and Impaired Fasting Glucose
}

\author{
Seyoung Kwon, Youngak Na \\ Department of Biomedical Laboratory Science, Daegu Health College, Daegu, Korea
}

\section{당뇨병 및 공복혈당장애 예측을 위한 당화혈색소 값}

\author{
권세영, 나영악 \\ 대구보건대학교 임상병리과
}

\begin{abstract}
There have been many studies to develop methods for predicting diabetes and to prevent diabetes. The validity of glycated hemoglobin $(\mathrm{HbA} 1 \mathrm{c})$, one of the commonly known tools in predicting diabetes, has been verified by many previous studies. In this study, we examined the cutoff value of $\mathrm{HbA} 1 \mathrm{c}$ for diabetes and impaired fasting glucose (IFG). Based on this study, we proposed a proper clinical guideline and evaluated the validation of the guideline. Excluding those without blood glucose and $\mathrm{HbA} 1 \mathrm{c}$ data, we used the data of 5,161 subjects (2,281 men and 2,880 women) over the age of 20 years from the 2015 Korean National Health and Nutrition Examination Survey. The correlation efficient of fasting plasma glucose (FPG) and $\mathrm{HbA} 1 \mathrm{c}$ was 0.79 , indicating a strong relationship. Howeve, the correlation efficient of FPG and HbA1c was low, showing 0.27 in non-diabetes, 0.39 in IFG, and 0.66 in diabetes, showing a strong relationship. The cutoff value of $\mathrm{HbA} 1 \mathrm{c}$ for predicting diabetes using ROC curve was $6.05 \%$ (sensitivity $84.6 \%$, and specificity 92.0\%), and AUC was 0.941 (0.937 in men, and 0.946 in women). The cutoff value of HbA1c for predicting IFG using ROC curve was $5.55 \%$ (sensitivity $64.5 \%$, and specificity $70.0 \%$ ), and AUC was 0.733 (0.708 in men, and 0.764 in women). Therefore, it may not be appropriate to apply the guidelines for diagnosing IFG since sensitivity and specificity were below $70 \%$. For future studies retarding the cutoff value of $\mathrm{HbA} 1 \mathrm{C}$ in predicting IFG, high sensitivity and specificity are expected if we segment the reference range of IFG.
\end{abstract}

Key words: Cutoff value, $\mathrm{HbA} 1 \mathrm{c}$, Diabetes, Impaired fasting glucose

This is an Open Access article distributed under the terms of the Creative Commons Attribution Non-Commercial License (http://creativecommons.org/licenses/by-nc/4.0) which permits unrestricted non-commercial use, distribution, and reproduction in any medium, provided the original work is properly cited.

Copyright @ 2017 The Korean Society for Clinical Laboratory Science. All rights reserved.
Corresponding author: Seyoung Kwon Department of Biomedical Laboratory Science, Daegu Health College, 15 Yeongsong-ro, Buk-gu, Daegu 41453, Korea

Tel: 82-53-320-1362

Fax: 82-53-320-1450

E-mail: sykwon@dhc.ac.kr

Received: April 30, 2017

Revised $1^{\text {st. }}:$ May 15, 2017

Revised $2^{\text {nd }}:$ May 15, 2017

Accepted: May 16, 2017

\section{서 론}

우리나라를 비롯해 전세계적으로 당뇨병의 유병율은 꾸준히 증가하고 있으며[1], 그로 인한 치료 및 합병증 예방을 위한 당뇨 병 관리와 함께 당뇨병을 조기에 발견하고, 당뇨병으로의 진행 을 막기 위해 당뇨병 전 단계(prediabetes) 대상자의 진단 및 관 리에 대한 관심도 증가하고 있다. 이에 따라 당뇨병 진단 뿐만 아 니라 당뇨병 고위험군, 당뇨병 전 단계 대상자를 조기에 발견하
고 예측할 수 있는 효과적인 방법이 필요하다. 지금까지 당화혈 색소는 당뇨병 진단 후 질환에 대한 모니터링 지표로 활용도가 컸으나, 만성 질병 예방의 중요성에 대한 인식이 커지면서 당뇨 병 진단 뿐 아니라 당뇨병 전 단계 대상자에 대한 선별과 진단에 대한 중요성도 강조되고 있다.

그 동안 당뇨병 진단을 위한 당화혈색소 값에 관한 연구는 꾸 준히 진행되어 왔으나, 검사법의 표준화 및 신뢰도 등의 문제로 당뇨병의 진단기준에는 포함되지 않다가[2], 최근에 미국을 비 
롯해 국내에서도 당뇨병의 진단기준에 당화혈색소가 포함되었 다[3-5]. 그 기준을 살펴보면 당뇨병 진단의 경우 당화혈색소 $6.5 \%$ 이상이며, $5.7 \sim 6.4 \%$ 에 해당하는 경우 당뇨병 위험 증가 로 보고 있다[4]. 그러나 여러 연구에서 연구대상자의 특성에 따 라 당화혈색소 값은 차이를 보이며[6,7], 당뇨병 예측을 위한 연 구는 많았으나 공복혈당장애 예측을 위한 연구는 많지 않은 실 정이다.

따라서 본 연구에서는 연구 대상자들의 당뇨군 및 공복혈당 장애군에 대한 당화혈색소 분별점을 살펴보고, 당뇨군 및 공복 혈당장애군 분별을 위한 적절한 임상 적용 기준에 대한 자료를 제시하고 이에 대한 타당성 여부를 평가해 보고자 하였다.

\section{재료 및 방법}

\section{1. 연구대상}

제 6기 3차년도 국민건강영양조사 자료에 해당하는 2015년 도 참여 대상자 7,380 명을 대상으로 당뇨 및 공복혈당장애에 대 한 당화혈색소 분별점을 산출하기 위해 해당 검사항목 측정치 를 포함하고 있는 대상자를 선정하였다. 전체 대상자 중 공복혈 당 측정치 누락자 833명, 당화혈색소 측정치 누락자 36명, 19세 이하 대상자를 제외하고 연구에 포함된 20세 이상 최종 대상자 5,161 명(남성 2,281명, 여성 2,880명)의 검진조사 자료를 활용 하여 분석을 시행하였다. 당해년도 조사 자료는 생명윤리법에 따라 국가가 직접 공공복리를 위해 수행하는 연구에 해당하여 연구윤리심의위원회 심의를 받지 않고 수행되었다[8].

\section{2. 연구 방법}

혈액 검사는 공복 상태에서 시행하였으며, 공복혈당은 Pureauto S GLU 시약으로 Hitachi 7600-210 (Hitachi high-technologies, Tokyo, Japan) 자동화학 분석기를 사용하 여 Hexokinase UV 법으로 측정하였다. 당화혈색소는 HLC-723G8 HbA1c 전용시약으로 Tosoh G8 (Tosoh, Tokyo, Japan)을 사용하여 고속액체크로마토그래피(HPLC, high performance liquid chromatography)법으로 측정하였다.

당대사이상 그룹의 분류는 미국당뇨병학회(American Diabetes Association, $\mathrm{ADA}$ )에서 제시하는 정의에 따라 공복 혈당농도 $<100 \mathrm{mg} / \mathrm{dL}$ 인 경우를 비당뇨군, $\geq 126 \mathrm{mg} / \mathrm{dL}$ 인 경 우를 당뇨군, 그 사이의 농도에 해당하는 경우를 공복혈당장애 군으로 나누었으며 [9], 이미 당뇨병 진단을 받았거나약물 및 치 료를 받고 있는 자는 당뇨군에 포함하였다.

\section{3. 통계분석}

공복혈당과 당화혈색소의 관련성을 살펴보기 위해 상관관계 는 당대사이상 그룹별로 나누어 Pearson's 상관계수를 비교하 였다. 당뇨군 및 공복혈당장애군에 대한 당화혈색소 분별점을 산출하기 위해 Receiver operating characteristic (ROC) curve를 이용하여 분석하고, 당화혈색소 각 농도별 민감도와 특이도를 살펴보았으며, Area under the curve (AUC)를 비교 하였다. 자료분석은 SPSS 17.0 (SPSS, Chicago, IL, USA)을 사 용하였고, 결과 해석 시 유의수준은 $p$ 값 0.05 미만으로 하였다.

\section{결 과}

\section{1. 공복혈당 농도에 따른 당 대사이상 그룹 분포}

당 대사이상 그룹의 분포는 남성의 경우 비당뇨군 1,238 명 (54.3\%), 공복혈당장애군 701명(30.7\%), 당뇨군 342명(15.0\%) 이었고, 여성의 경우 비당뇨군 1,966명(68.3\%), 공복혈당장애 군 608명(21.1\%), 당뇨군 306명(10.6\%)으로 나타나 공복혈당 장애 및 당뇨병 위험 대상자 비율은 여성보다 남성에서 더 높았 다(Table 1).

\section{2. 공복혈당과 당화혈색소의 관련성}

대상자 전체의 공복혈당과 당화혈색소의 상관계수는 0.79 이 었으며, 남성의 경우 0.77 , 여성의 경우 0.81 으로 나타나 여성에 서 상관성이 더 높았다. 비당뇨군에서 공복혈당과 당화혈색소 의 상관계수는 0.27 , 공복혈당장애군에서는 0.39 , 당뇨군에서

Table 1. Distribution and correlation coefficients of fasting glucose and HbA1caccording to categories

\begin{tabular}{|c|c|c|c|c|c|c|c|c|}
\hline & \multicolumn{2}{|c|}{ All } & \multicolumn{2}{|c|}{ Non-DM } & \multicolumn{2}{|c|}{ IFG } & \multicolumn{2}{|c|}{$\mathrm{DM}$} \\
\hline & $\mathrm{N}$ & $r$ & N & $r$ & N & $r$ & N & $r$ \\
\hline All & 5,161 & $0.79^{\star \star}$ & 3,204 & $0.27^{\star \star}$ & 1,309 & $0.39^{\star \star}$ & 648 & $0.66^{\star \star}$ \\
\hline Men & 2,281 & $0.77^{\star \star}$ & 1,238 & $0.20^{\star \star}$ & 701 & $0.40^{\star \star}$ & 342 & $0.64^{* *}$ \\
\hline Women & 2,880 & $0.81^{\star \star}$ & 1,966 & $0.32^{\star \star}$ & 608 & $0.40^{\star \star}$ & 306 & $0.68^{\star \star}$ \\
\hline
\end{tabular}

**Pearson's correlation test $(p<0.01)$.

Abbreviation: r, correlation coefficients; DM, diabetes mellitus; IFG, impaired fasting glucose. 
A

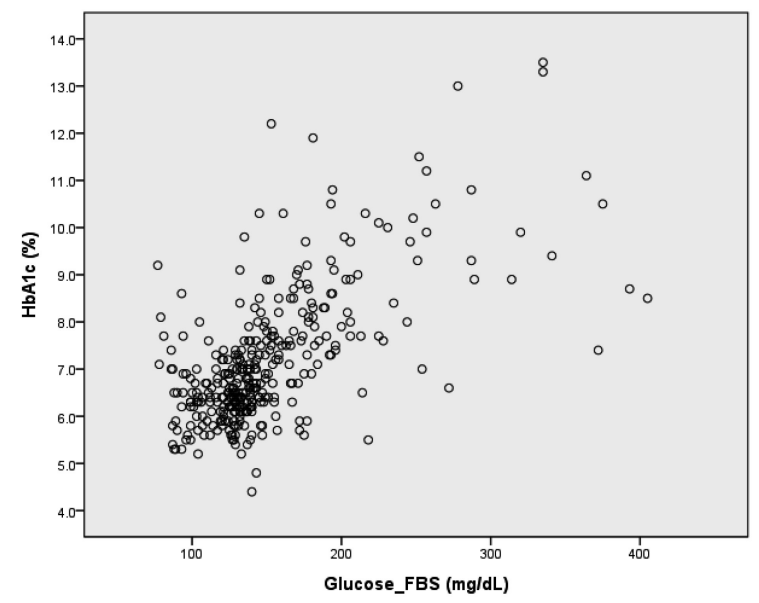

C

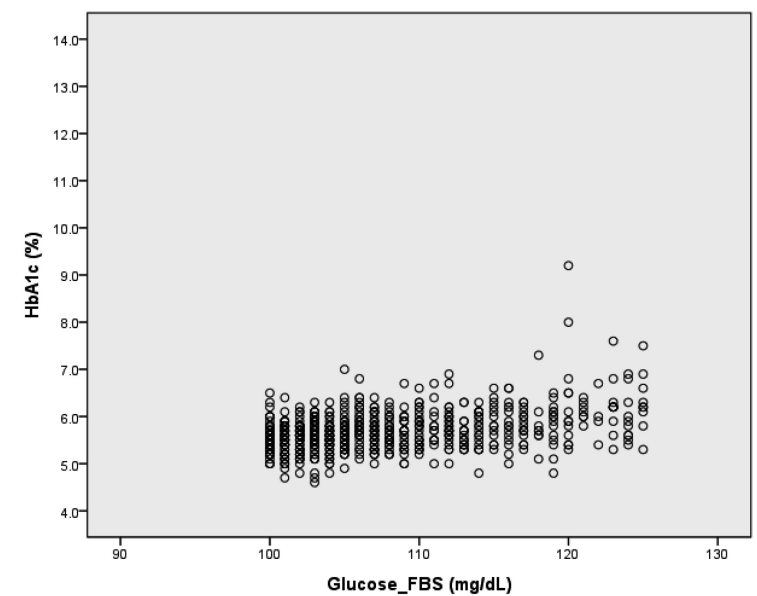

B

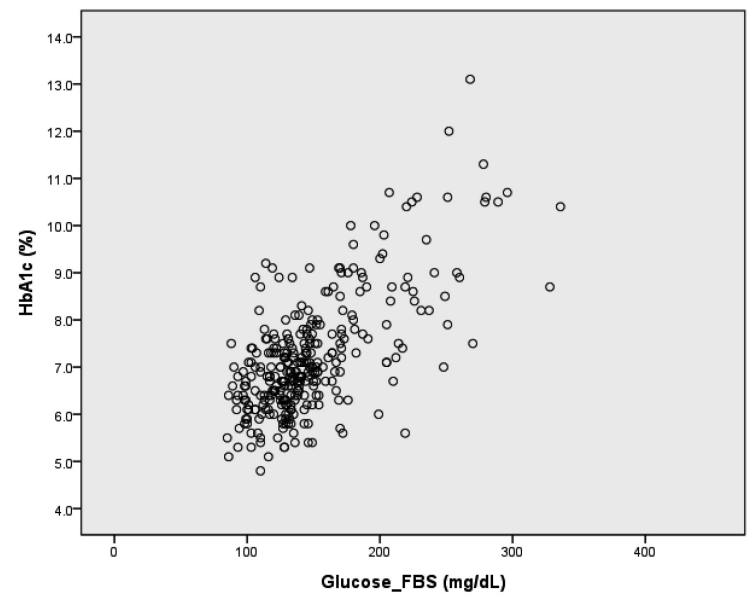

D

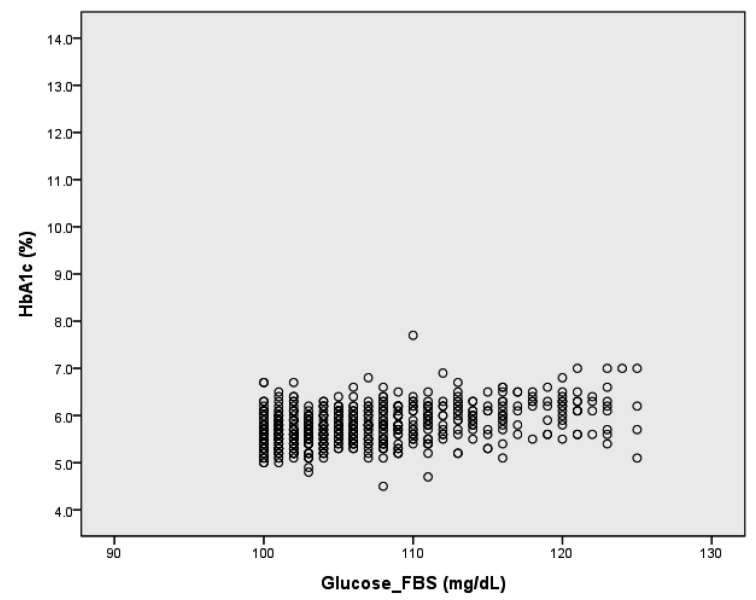

Figure 1. Scatter plot of individuals according to $\mathrm{HbA1c}$ and fasting blood glucose level. Correlation coefficient was 0.644 in men with $\mathrm{DM}(\mathrm{A}), 0.676$ in women with DM (B), 0.399 in men with IFG (C), and 0.403 in women with IFG (D).

는 0.66 으로 나타나 당뇨군에서 상관성이 가장 높았으며 통계 적으로 유의하였다. 각 군 모두 남성보다 여성에서 더 높은 상관 성을 보였다(Table 1, Figure 1).

\section{3. 당뇨병 예측을 위한 당화혈색소 분별점}

ROC curve를 이용하여 당뇨병을 예측하기 위한 당화혈색소 분석 시, cutoff값은 $6.05 \%$ 로 남녀 동일하였고, 전체 대상자에 서 sensitivity $84.6 \%$, specificity $92.0 \%$ 였고, 남성의 경우 sensitivity $83.3 \%$, specificity $92.4 \%$, 여성의 경우 sensitivity $85.9 \%$, specificity $91.6 \%$ 였다(Table 2). AUC는 남성의 경우 0.937 , 여성의 경우 0.946 으로 남성보다 여성에서 더 높게 나타 났다(Figure 2A, B).

\section{4. 공복혈당장애 예측을 위한 당화혈색소 분별점}

$\mathrm{ROC}$ curve를 이용하여 공복혈당장애를 예측하기 위한 당화
혈색소 분석 시, cutoff값은 5.55\%로 남녀 동일하였고, 전체 대 상자에서 sensitivity $64.5 \%$, specificity $70.0 \%$ 였고, 남성의 경 우 sensitivity $59.3 \%$, specificity $71.5 \%$, 여성의 경우 sensitivity $70.4 \%$, specificity $69.1 \%$ 였다(Table 3). AUC는 남 성의 경우 0.708 , 여성의 경우 0.764 로 남성보다 여성에서 더 높게 나타났다(Figure 2C, D).

\section{고 찰}

본 연구에서는 우리나라 성인을 대상으로 표본 추출하여 대 표성을 띠는 데이터를 이용하여 당뇨군에 대한 당화혈색소 분 별점을 살펴봄으로써 기존 판정 기준을 검증함과 동시에 증가 하는 공복혈당장애군 예측을 위한 당화혈색소 분별점에 대한 적절한 임상 적용 기준에 대한 타당성 여부를 평가해 보고자 하 였다. 
Table 2. Comparison of sensitivity and specificity for predicting diabetes based on fasting glucose at HbA1c levels

\begin{tabular}{|c|c|c|c|c|c|c|}
\hline \multirow{2}{*}{$\begin{array}{c}\mathrm{HbA} 1 \mathrm{c} \\
(\%)\end{array}$} & \multicolumn{2}{|c|}{ All } & \multicolumn{2}{|c|}{ Men } & \multicolumn{2}{|c|}{ Women } \\
\hline & Sensitivity (\%) & Specificity (\%) & Sensitivity (\%) & Specificity (\%) & Sensitivity (\%) & Specificity (\%) \\
\hline 5.75 & 91.8 & 78.4 & 90.9 & 78.1 & 92.8 & 78.6 \\
\hline 5.85 & 88.9 & 84.9 & 87.7 & 84.9 & 90.2 & 84.8 \\
\hline 5.95 & 86.4 & 88.8 & 84.8 & 89.5 & 88.2 & 88.2 \\
\hline 6.05 & 84.6 & 92.0 & 83.3 & 92.4 & 85.9 & 91.6 \\
\hline 6.15 & 81.2 & 94.6 & 79.8 & 94.7 & 82.7 & 94.4 \\
\hline 6.25 & 77.5 & 96.7 & 75.4 & 96.6 & 79.7 & 96.7 \\
\hline 6.35 & 72.5 & 98.0 & 69.9 & 97.8 & 75.5 & 98.2 \\
\hline 6.45 & 67.3 & 98.7 & 64.0 & 98.6 & 70.9 & 98.8 \\
\hline 6.55 & 63.3 & 99.0 & 59.1 & 98.8 & 68.0 & 99.3 \\
\hline 6.65 & 60.3 & 99.3 & 56.1 & 99.0 & 65.0 & 99.5 \\
\hline 6.75 & 55.6 & 99.5 & 52.0 & 99.2 & 59.5 & 99.7 \\
\hline
\end{tabular}

A

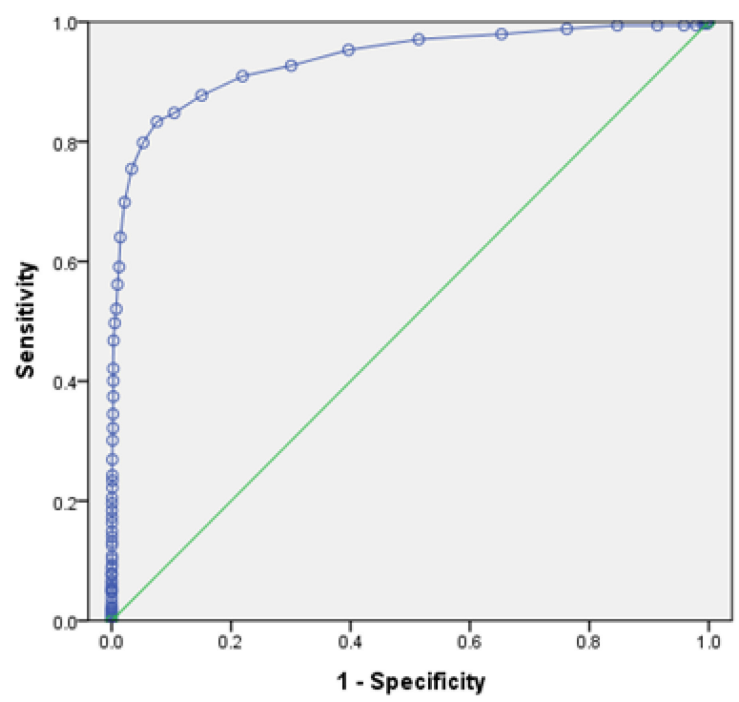

C

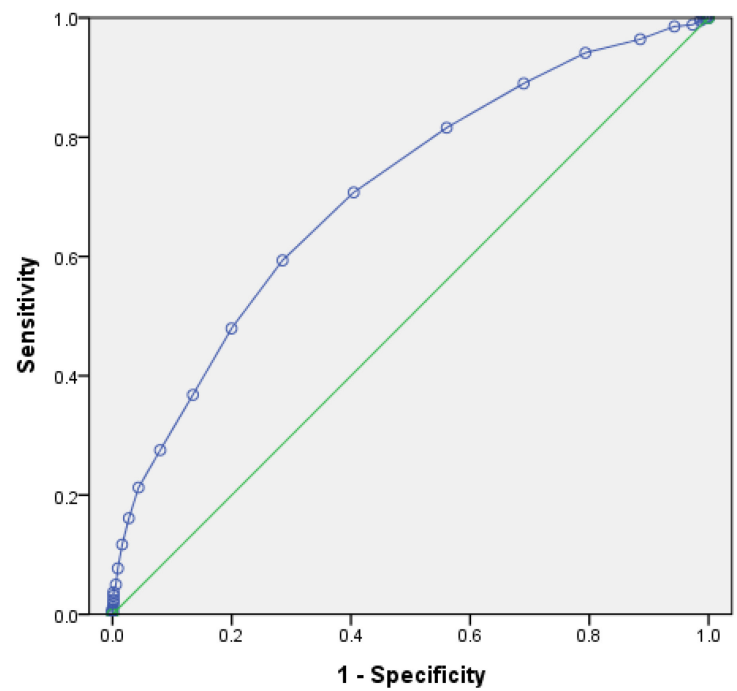

B

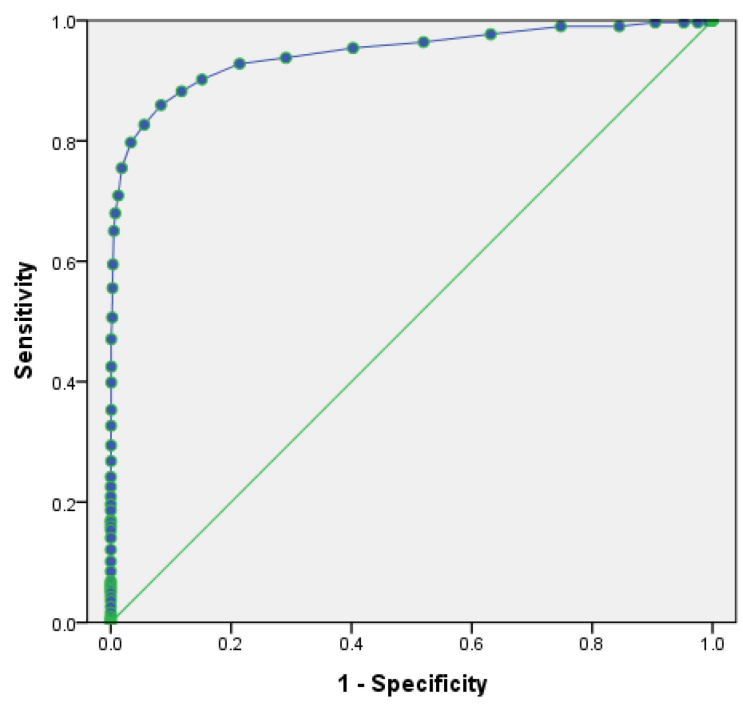

D

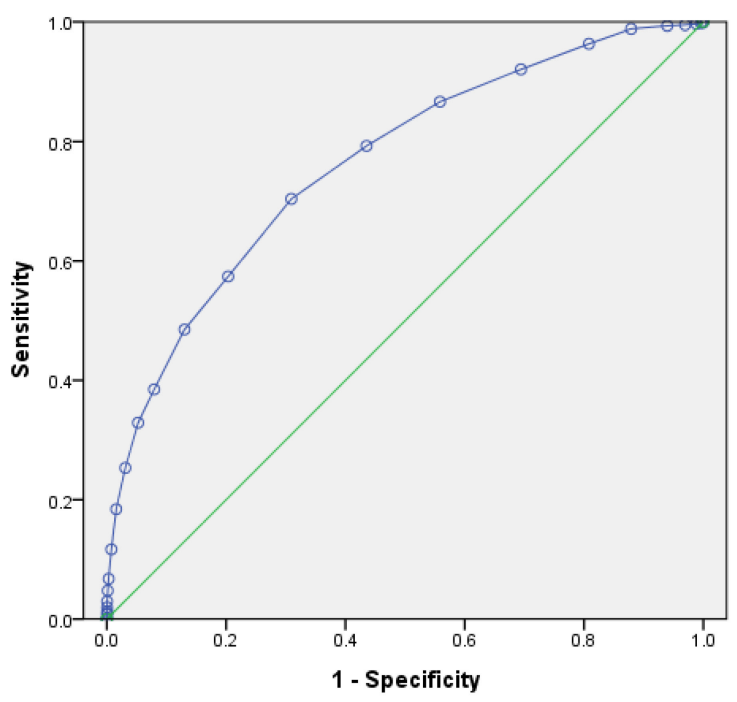

Figure 2. Receiver operating characteristic curve for HbA1c corresponding diabetes mellitus (use Youden's index). The value of AUC was as follows: A) 0.937 in men with DM, B) 0.946 in women with DM, C) 0.708 in men with IFG, D) 0.764 in women with IFG. 
118 Seyoung Kwon and Youngak Na. Cutoff Value of HbA1c for Predicting Diabetes and IFG

Table 3. Comparison of sensitivity and specificity for predicting impaired fasting glucose based on fasting glucose at HbA1c levels

\begin{tabular}{|c|c|c|c|c|c|c|}
\hline \multirow{2}{*}{$\begin{array}{c}\mathrm{HbA} 1 \mathrm{c} \\
(\%)\end{array}$} & \multicolumn{2}{|c|}{ All } & \multicolumn{2}{|c|}{ Men } & \multicolumn{2}{|c|}{ Women } \\
\hline & Sensitivity (\%) & Specificity (\%) & Sensitivity (\%) & Specificity (\%) & Sensitivity (\%) & Specificity (\%) \\
\hline 5.15 & 95.2 & 19.8 & 94.2 & 20.7 & 96.4 & 19.2 \\
\hline 5.25 & 90.5 & 30.7 & 89.0 & 31.0 & 92.1 & 30.6 \\
\hline 5.35 & 84.0 & 44.1 & 81.6 & 43.9 & 86.7 & 44.2 \\
\hline 5.45 & 74.7 & 57.6 & 70.8 & 59.5 & 79.3 & 56.5 \\
\hline 5.55 & 64.5 & 70.0 & 59.3 & 71.5 & 70.4 & 69.1 \\
\hline 5.65 & 52.3 & 79.8 & 47.9 & 80.0 & 57.4 & 79.7 \\
\hline 5.75 & 42.2 & 86.8 & 36.8 & 86.5 & 48.5 & 87.0 \\
\hline 5.85 & 32.6 & 92.0 & 27.5 & 92.0 & 38.5 & 92.1 \\
\hline 5.95 & 26.7 & 95.1 & 21.3 & 95.6 & 32.9 & 94.8 \\
\hline
\end{tabular}

당화혈색소는 공복혈당과의 상관성이 높아 당뇨병 진단 기 준으로 자리잡고 있다. 30세 이상의 당뇨 기진단자를 제외한 성 인을 대상으로 한 연구에서 공복혈당과 당화혈색소의 상관계수 는 0.820으로 나타났고[10], 본 연구 대상자 전체의 공복혈당과 당화혈색소의 상관계수는 0.79 로 나타나 강한 상관성이 입증되 었다. 그러나 당 대사 이상군별로 살펴보았을 때 비당뇨군에서 공복혈당과 당화혈색소의 상관계수는 0.27 , 공복혈당장애군에 서는 0.39 , 당뇨군에서는 0.66 으로 나타나 당뇨군에서 상관성 이 가장 높은 반면, 비당뇨군과 공복혈당장애군에서는 통계적 으로 유의하였지만 상관성은 상대적으로 낮았다. 이는 혈당치 분포에 따라 혈당조절지표를 평가한 연구에서 혈당치 100 $\mathrm{mg} / \mathrm{dL}$ 이하 구간과 $100 \sim 125 \mathrm{mg} / \mathrm{dL}$ 이하 구간에서는 혈당과 당화혈색소 보다 프록토사민과 $1,5-\mathrm{AG}$ 의 상관성이 나타난 결 과[11]와 유사하였으며 이는 비당뇨군과 공복혈당장애군에서 는 당화혈색소와의 관련성 해석에 참고할 필요가 있다.

또한 본 연구 데이터에서 식후 2시간 혈당 수치는 포함되지 않아 공복혈당과 당화혈색소와의 상관성만 살펴보았지만, 10,111 명을 대상으로 한 대규모 지역사회 연구에서 공복혈당 과 당화혈색소의 상관계수는 0.51 , 식후 2 시간 혈당과의 상관 계수는 0.33 이었고[12], 임신성 당뇨 진단을 위한 당부하검사 연구에서 채혈 시점별 상관성에서도 혈당과 당화혈색소의 상관 계수는 경구 당부하 1 시간후 $(\mathrm{r}=0.536), 2$ 시간후(r=0.541), 3시 간후(r=0.413)보다 공복 혈당과의 상관계수가 0.569 로 가장 높 게 나타나[13] 본 연구에 포함된 공복 혈당이 당화혈색소와 더 높은 상관성이 입증된 변수로서 상관성 해석에는 무리가 없을 것으로 보인다.

그 동안 당뇨와 당화혈색소 분별점에 대한 연구는 꾸준히 진 행되어 왔는데, 미국에서 행해진 6년간의 추적 연구에서 당 대 사 이상에 대한 선별 기준은 당화혈색소 $5.8 \%$, 당뇨병 전 단계 진단 기준은 $6.1 \sim 6.8 \%$, 당뇨병 진단 기준은 $7 \%$ 이상으로 제시 하였다[14]. 그러나, 당화혈색소는 아시아인이 백인보다 높은
경향이 있고, 인종에 따른 차이가 있음이 보고되고 있어 $[15,16]$ 우리나라 성인을 대상으로 한 연구 결과를 토대로 이에 맞는 기 준을 설정하는 것이 타당할 것이다. 실제로 10,111 명 대상의 연 구에서 공복혈당과 당화혈색소의 분별점은 5.95\%였으며[12], 일개 대학병원 종합검진센터 내원 환자를 대상으로 한 연구에 서 결과는 $5.95 \%$ 결과로 나타나 $6.0 \%$ 값을 고려해야 한다고 제 시하였다[17].

본 연구에서 ROC curve를 이용하여 당뇨병을 예측하기 위 한 당화혈색소 cutoff값은 남녀 모두 6.05\% (sensitivity 84.6\%, specificity 92.0\%)로 나타났는데, 이는 당뇨 위험을 가진 392 명을 대상으로 한 연구에서 당뇨 진단을 위한 당화혈색소 분별 점 6.1\% (민감도 $81.8 \%$, 특이도 $84.9 \%$ )[18], 일개병원에서 당 뇨 미진단자 405 명을 대상으로 경구 당부하검사를 통해 나타난 당화혈색소 분별점 $6.1 \%$ (민감도 $77.8 \%$, 특이도 $71.7 \%$ )[19], 당뇨 미진단자 4,616명을 대상으로 한 다른 연구에서 당화혈색 소 분별점 $6.1 \%$ (민감도 $63.8 \%$, 특이도 $88.1 \%$ ) [20]와 연구 결 과가 일치하였으며 본 연구에서 민감도와 특이도가 더 높게 나 타났다. 또한 현재 당뇨병 진단 기준에 해당하는 당화혈색소 $6.5 \%$ 는 본 연구에서도 특이도 $99 \%$ 로 나타나 진단적인 측면에 서 그대로 유지함이 타당하나 민감도 $90 \%$ 이상을 고려할 수 있 는 당화혈색소 기준은 5.8\%로 낮아짐을 알 수 있었다.

반면에 당뇨 기진단자를 제외한 국내 연구에서는 ROC 분석 결과 AUC 0.977 이며 당뇨 분별점은 6.35\% (sensitivity 86.9\%, specificity 99.1\%)로 나타났고[21], 당뇨 합병증으로 당뇨병성 망막증을 진단하기 위한 적정 분별점은 $6.5 \%$ 까지 제시하기도 하였다[22]. 이처럼 당뇨병 예측을 위한 당화혈색소 분별점은 연구대상자의 특성에 따라 다양하게 제시되어 왔으나, 본 연구 대상자가 일개 지역 병원 수검자가 아니라 우리나라 성인 집단 의 인구 구성을 반영한 표본임을 감안하여 참고할 만한 기준이 될 수 있을 것이다.

한편 그 동안 당뇨병에 비해 공복혈당장애를 예측할 수 있는 
당화혈색소의 기준 연구는 많지 않았으나, 당화혈색소 $5.5 \%$ 미 만 대상자에 비해 5.5 6.4\%에 해당하는 대상자가 당뇨에 이환 될 위험이 2.66배라는 보고[23]와 더불어 당뇨병 고위험에 해 당하는 공복혈당장애를 미리 진단하기 위한 당화혈색소 관련 연구도 진행되고 있다. 당뇨 미진단자 4,616명을 대상으로 한 연구에서 당뇨병 전 단계 진단을 위한 분별점은 $5.7 \%$ (민감도 $48.6 \%$, 특이도 $65.7 \%$ )였고[20], 당뇨 기진단자를 제외한 국내 연구에서 공복혈당장애와 당화혈색소의 $\mathrm{ROC}$ 분석 결과 $\mathrm{AUC}$ 는 0.760 , 그 분별점은 $5.65 \%$ (sensitivity $69.3 \%$, specificity 71.0\%)로 제시하였다[21]. 또한 6년간의 지역사회 연구에서 당 뇨로 발전할 위험의 적절 분별점은 $5.6 \%$ 라고 제시하였는데 [24], 이는 본 연구에서 ROC curve를 이용한 공복혈당장애 예 측 당화혈색소 cutoff값 $5.55 \%$ (sensitivity $64.5 \%$, specificity $70.0 \%$ )와 유사하였다. 한편 당뇨 기진단자를 제외한 당뇨 고위 험군 35,624 명을 대상으로 한 연구에서 당뇨병 전 단계 선별을 위한 분별점은 $5.4 \%$ (민감도 63\%, 특이도 $65 \%$ ) 였고, 동일 연구 에서 당화혈색소 $5.7 \%$ 에서 민감도 $35 \%$, 특이도 $88 \%$ 로 나타나 [25] 본 연구에서 보다 낮은 분별점과 민감도 및 특이도를 보이 기도 하였다. 이는 대상자가 일반 집단이 아닌 당뇨병 고위험군 을 대상으로 하였기에 선별 분별점이 더 낮아진 것으로 보인다.

본 연구에서 공복혈당장애 예측을 위한 $\mathrm{ROC}$ 분석 결과 $\mathrm{AUC}$ 는 0.733 (남성의 경우 0.708 , 여성의 경우 0.764)으로 나타나 당뇨병 예측을 위한 분석에서 나타난 AUC 0.941 (남성의 경우 0.937 , 여성의 경우 0.946 ) 보다 낮고, 민감도와 특이도 또한 $70 \%$ 이하로 낮게 나와 공복혈당장애 진단 기준으로 적용하기 에는 무리가 있을 것이다. 이는 공복혈당장애군에 해당하는 공 복혈당 농도가 $100 \mathrm{mg} / \mathrm{dL}$ 이상, $126 \mathrm{mg} / \mathrm{dL}$ 미만으로 넓은 범 위에서 당뇨병 전 단계로 분류되기에 과다 추정될 수 있고, 이로 인해 당화혈색소와의 관련성에 있어 그 분별점에 낮은 민감도 와 특이도를 보였다고 생각한다. 추후 공복혈당장애 예측을 위 한 분별점의 연구에서는 현재 넓게 설정된 공복혈당범위를 세 분화하여 분석에 적용하면 좀 더 민감도와 특이도가 높은 분별 점을 설정할 수 있을 것으로 보인다.

본 연구는 인구 집단에 있어서 대표성을 띠기는 하나 단면 연 구임을 감안해야 하고 일반적인 기준 자료를 제시하고자 당뇨 기진단자 및 소수의 혈색소 병증 및 기타 질환자도 대상자에 포 함되어 있으므로 해석에 있어 참고해야 한다. 더 정확한 분석을 위해서는 당뇨 관련 기저 질환자를 제외해야 함이 타당하나 결 과를 제시하지는 않았지만, 당뇨 기 진단자를 제외한 분별점 분 석에서도 본 연구 결과와 거의 차이가 없었다. 따라서 지금까지
국가 단위의 대규모 데이터를 이용한 당화혈색소 분별점 연구 나 공복혈당장애군에 대한 분별점 분석이 많지 않았기에 현재 증가하는 당뇨병 및 공복혈당장애군을 예측할 수 있는 당화혈 색소의 분별점 설정을 위한 기초 자료를 제시하였음에 의의가 있을 것이다. 추후 연구대상자 및 다양한 자료를 보완하여 우리 나라 성인 대상의 당뇨 및 공복혈당장애 예측에 필요한 체계적 인 연구가 지속적으로 필요하다고 생각된다.

\section{요 약}

증가하고 있는 당뇨병을 예방하기 위한 연구와 함께 당뇨병 의 진단 및 예측을 할 수 있는 방법에 대한 연구도 꾸준히 진행되 고 있다. 가장 널리 알려져 있는 당화혈색소는 여러 선행 연구에 서 그 타당성이 검증되었다. 본 연구에서는 당뇨군 및 공복혈당 장애군에 대한 당화혈색소 분별점을 살펴보고, 당뇨군 및 공복 혈당장애군 분별을 위한 적절한 임상 적용 기준에 대한 자료를 제시하고 이에 대한 타당성 여부를 평가해 보고자 하였다. 2015 국민건강영양조사 데이터 중 측정치 누락자를 제외한 20세 이 상 대상자 5,161명(남성 2,281명, 여성 2,880명)의 자료를 이 용하였다. 대상자 전체의 공복혈당과 당화혈색소의 상관계수 는 0.79 로 나타나 강한 상관성이 입증되었다. 그러나 비당뇨군 에서 공복혈당과 당화혈색소의 상관계수는 0.27 , 공복혈당장 애군에서는 0.39 , 당뇨군에서는 0.66 으로 나타나 당뇨군에서 는 상관성이 높은 반면, 비당뇨군과 공복혈당장애군에서 상관 계수는 상대적으로 낮았다. ROC curve를 이용하여 당뇨병을 예측하기 위한 당화혈색소 cutoff값은 남녀 모두 6.05\% (sensitivity 84.6\%, specificity 92.0\%)로 나타났으며, AUC는 0.941 (남성의 경우 0.937 , 여성의 경우 0.946)이었다. 반면에 공복혈당장애를 예측하기 위한 당화혈색소 cutoff값은 5.55\% (sensitivity 64.5\%, specificity 70.0\%), AUC는 0.733 (남성의 경우 0.708 , 여성의 경우 0.764 )으로 나타났다. 이로써 민감도 와 특이도 모두 $70 \%$ 이하로 낮게 나온 공복혈당장애의 경우 진 단 기준으로 적용하기에는 무리가 있다. 추후 공복혈당장애 예 측을 위한 분별점의 연구에서는 공복혈당범위를 세분화하여 적 용하면 좀 더 민감도와 특이도가 높은 분별점을 설정할 수 있을 것으로 보인다.

\section{Acknowledgements: None \\ Funding: None \\ Conflict of interest: None}




\section{REFERENCES}

1. Kim DJ. The epidemiology of diabetes in Korea. Diabetes Metab J. 2011;35(4):303-308.

2. American Diabetes Association. Report of the expert committee on the diagnosis and classification of diabetes mellitus. Diabetes Care. 1997;20(7):1183-1197.

3. International Expert Committee. International expert committee report on the role of the A1c assay in the diagnosis of diabetes. Diabetes Care. 2009;32(7):1327-1334.

4. American Diabetes Association. Diagnosis and classification of diabetes mellitus. Diabetes Care. 2010;33(Suppl 1):62-69.

5. Ko SH, Kim SR, Kim DJ, Oh SJ, Lee HJ, Shim KH, et al. Committee of Clinical Practice Guidelines, Korean Diabetes Association. 2011 Clinical practice guidelines for type 2 diabetes in Korea. Diabetes Metab J. 2011;35(5):431-436.

6. Cowie CC, Rust KF, Byrd-Holt DD, Gregg EW, Ford ES, Geiss LS, et al. Prevalence of diabetes and high risk for diabetes using A1C criteria in the U.S. population in 1988-2006. Diabetes Care. 2010;33(3):562-568.

7. Herman WH, Ma Y, Uwaifo G, Haffner S, Kahn SE, Horton ES, et al. Diabetes Prevention Program Research Group. Differences in $\mathrm{A} 1 \mathrm{C}$ by race and ethnicity among patients with impaired glucose tolerance in the Diabetes Prevention Program. Diabetes Care. 2007;30(10):2453-2457.

8. Korea Centers for Disease Control and Prevention. The Sixth Korea National Health and Nutrition Examination Survey (KNHANES VI-3) [Internet]. Cheongju: Korea Centers for Disease Control and Prevention; 2015 [cited 2017 April 10]. Available from: https://knhanes.cdc.go.kr/knhanes/index.do

9. American Diabetes Association. Diagnosis and classification of diabetes mellitus. Diabetes Care. 2004;27(suppl 1):5-10.

10. Jeon JY, Ko SH, Kwon HS, Kim NH, Kim JH, Kim CS, et al. Prevalence of diabetes and prediabetes according to fasting plasma glucose and HbA1c. Diabetes Metab J. 2013;37(5): 349-357.

11. Kwon PS, Rheem IS. The assessment of blood glucose distribution according to the fasting state and glycemic control indicators for diabetes screening. Korean J Clin Lab Sci. 2016; 48(4):312-320.

12. Kim JH, Kim GW, Lee MY, Shin JY, Shin YG, Koh SB, et al. Role of HbA1c in the screening of diabetes mellitus in a Korean rural community. Diabetes Metab J. 2012;36(1):37-42.

13. Ryu AJ, Moon HJ, Na JO, Na YJ Kim, Kim SJ, Mo SI, et al. The usefulness of the glycosylated hemoglobin level for the diag- nosis of gestational diabetes mellitus in the Korean population. Diabetes Metab J. 2015;39(6):507-511.

14. Buell C, Kermah D, Davidson MB. Utility of A1C for diabetes screening in the 1999-2004 NHANES population. Diabetes Care. 2007;30(9):2233-2235.

15. Herman WH, Ma Y, Uwaifo G, Haffner S, Kahn SE, Horton ES, et al. Differences in A1C by race and ethnicity among patients with impaired glucose tolerance in the Diabetes Prevention Program. Diabetes Care. 2007;30(10):2453-2457.

16. Ziemer DC, Kolm P, Weintraub WS, Vaccarino V, Rhee MK, Twombly JG, et al. Glucose-independent, black-white differences in hemoglobin A1c levels: a cross-sectional analysis of 2 studies. Ann Intern Med. 2010;152(12):770-777.

17. Bae JC, Rhee EJ, Choi ES, Kim JH, Kim WJ, Yoo SH, et al. The cutoff value of $\mathrm{HbA1c}$ in predicting diabetes in Korean adults in a university hospital in Seoul. Korean Diabetes J. 2009;33(6): 503-510.

18. Kim KS, Kim SK, Lee YK, Park SW, Cho YW. Diagnostic value of glycated hemoglobin (HbA1c) for the early detection of diabetes in high risk subjects. Diabet Med. 2008;25(8):997-1000.

19. Lee YS, Moon SS. The use of HbA1c for diagnosis of type 2 diabetes in Korea. Korean J Med. 2011;80(3):291-297.

20. Lee H, Oh JY, Sung YA, Kim DJ, Kim SH, Kim SG, et al. Optimal hemoglobin A1C cutoff value for diagnosing type 2 diabetes mellitus in Korean adults. Diabetes Res Clin Pract. 2013;99(2): 231-236.

21. Hong SM, Kang JG, Kim CS, Lee SN, Park CY, Lee CB, et al. Glycosylated hemoglobin threshold for predicting diabetes and prediabetes from the fifth Korea National Health and Nutrition Examination Survey. Diabetes Metab J. 2016;40(2):167-170.

22. Cho NH, Kim TH, Woo SJ, Park KH, Lim S, Cho YM, et al. Optimal HbA1c cutoff for detecting diabetic retinopathy. Acta Diabetol. 2013;50(6):837-842.

23. Lim NK, Park SH, Choi SJ, Lee KS, Park HY. A risk score for predicting the incidence of type 2 diabetes in a middle-aged Korean cohort: the Korean genome and epidemiology study. Circ J. 2012;76(8):1904-1910.

24. Choi SH, Kim TH, Lim S, Park KS, Jang HC, Cho NH. Hemoglobin A1c as a diagnostic tool for diabetes screening and new-onset diabetes prediction: a 6-year community-based prospective study. Diabetes Care 2011;34(4):944-949.

25. Kim HK, Bae SJ, Choe JO. Impact of HbA1c criterion on the detection of subjects with increased risk for diabetes among health check-up recipients in Korea. Diabetes Metab J. 2012;36(2):151-156. 